\section{Effectiveness of Alcohol-Based Hand Hygiene Gels in Reducing Nosocomial Infection Rates}

To the Editor-We have read with great interest the article by Rupp et al. ${ }^{1}$ The results challenge current infection control policies. ${ }^{2}$ The study has been carefully conducted and the results appear to be valid. Surprisingly, the improved compliance with hand hygiene recommendations associated with the use of alcohol-based hand hygiene products did not result in lower nosocomial infection rates. As the authors pointed out, the results may be interpreted in several ways. We want to add points to be discussed that may be associated with or even responsible for these negative results.

First, the level of antimicrobial efficacy of $62 \%$ ethanol may not suffice to interrupt transmission of nosocomial pathogens. In fact, the product does not meet the requirement of European standard EN 1500, ${ }^{3}$ which is needed to clear the product for the European market. ${ }^{4}$ Incidentally, the exact concentration of the ethanol is not described by Rupp et al ${ }^{1}$ : it may be $62 \%$ by volume (equivalent to $49 \mathrm{~g} / \mathrm{dL}$ ) or $62 \%$ by weight. Second, we have shown that training in the application of alcohol-based hand hygiene products is crucial to optimize antimicrobial killing..$^{5,6}$ No formal training is described by Rupp et $\mathrm{al}^{1}$; an absence of training may have reduced the effect of the gel. Third, coagulase-negative staphylococci were cultured mainly from the hands of healthcare workers. However, data regarding detection of clinically important pathogens such as methicillin-resistant Staphylococcus aureus are not given. Finally, a formal sample size calculation was not mentioned, and lack of this calculation potentially limits the impact of the negative results of the trial. The low baseline rate of nosocomial infection may have jeopardized the possibility of detecting the clinical effect of the introduction of the gel. In addition, under conditions of high patient occupancy or understaffing, hand hygiene alone is unlikely to prevent nosocomial infection.?

We congratulate the authors for conducting this important trial. It may be the first hint that the antimicrobial activity of such gels is not sufficient to reduce the incidence of nosocomial infections.

\section{ACKNOWLEDGMENTS}

Potential conflicts of interest. All authors report no conflicts of interest relevant to this article.

Andreas F. Widmer, MD, MS; Manfred Rotter, MD
From the Division of Infectious Diseases \& Hospital Epidemiology, University of Basel Hospitals, Basel, Switzerland (A.F.W.); and the Institute of Hygiene and Medical Microbiology, Medical University Vienna, Vienna, Austria (M.R.).

Address reprint requests to Andreas F. Widmer, MD, MS, University of Basel, Basel, BS 4031 Switzerland (awidmer@uhbs.ch).

Infect Control Hosp Epidemiol 2008; 29:576

(C) 2008 by The Society for Healthcare Epidemiology of America. All rights reserved. 0899-823X/2008/2906-0019\$15.00. DOI: $10.1086 / 587808$

\section{REFERENCES}

1. Rupp ME, Fitzgerald T, Puumala S, et al. Prospective, controlled, crossover trial of alcohol-based hand gel in critical care units. Infect Control Hosp Epidemiol 2008;29:8-15.

2. Widmer AF. Replace hand washing with use of a waterless alcohol hand rub? Clin Infect Dis 2000;31:136-143.

3. Rotter ML. European norms in hand hygiene. J Hosp Infect 2004;56(sup$\mathrm{pl} 2):$ S6-S9.

4. Kramer A, Rudolph P, Kampf G, Pittet D. Limited efficacy of alcohol-based hand gels. Lancet 2002;359:1489-1490.

5. Widmer AF, Conzelmann M, Tomic M, Frei R, Stranden AM. Introducing alcohol-based hand rub for hand hygiene: the critical need for training. Infect Control Hosp Epidemiol 2007;28:50-54.

6. Widmer AE, Dangel M. Alcohol-based handrub: evaluation of technique and microbiological efficacy with international infection control professionals. Infect Control Hosp Epidemiol 2004;25:207-209.

7. Beggs CB, Noakes CJ, Shepherd SJ, Kerr KG, Sleigh PA, Banfield K. The influence of nurse cohorting on hand hygiene effectiveness. Am J Infect Control. 2006;34:621-626.

\section{"Cannot Detect a Change" Is Not the Same as "There Is Not a Change"}

To the Editor-The recent article by Rupp et al, ${ }^{1}$ has generated a great deal of media attention. Unfortunately, the value of the article in terms of increasing hand hygiene compliance, use of alcohol-based hand gel, and useful adherence data from observations was lost. However, we believe the following remarks provide evidence that the conclusion of "no detectable change" in nosocomial infection rates may not be supported by their analysis.

The authors had a null hypothesis of "no change" and an alternative of "change." They have concluded that their findings support the null hypothesis. What this means is that there is not enough evidence to overturn the null hypothesis-but that is not the same as saying that the null hypothesis is true. If you collect very few data or assemble a very uninformative data set, then it is unlikely that you will have enough evidence to overturn the null hypothesis-even if it should be overturned.

There are so few infections over the time period in the study ${ }^{1}$ that the data sets are likely to be uninformative with respect to the question of infection rates. These units had 12 beds, and the 